\title{
Research on the models and implementation techniques of ceramic MES system Based on ISA95
}

\author{
Liping Zhang ${ }^{1,2}$, Xiaolong Yang ${ }^{1,2}$, Yongqian $\mathrm{Xu}^{1,2}$ and Quanwang $\mathrm{Yu}^{1,2, *}$ \\ ${ }^{1}$ Institute of Intelligent Manufacturing, Guangdong Academy of Sciences. Guangzhou, Guangdong, 510000, China. \\ ${ }^{2}$ Guangdong Key Laboratory of modern control technology. Guangzhou, Guangdong, 510000, China.
}

\begin{abstract}
This paper is based on ISA95, combined with the problems existing in the production process of ceramic products, to study the models and implementation techniques of ceramic MES system. It has realized the high flexibility and intelligence of ceramic manufacturing, and the traceability of ceramic products, as well as has improved the information level of the ceramic industry.
\end{abstract}

\section{Introduction}

There are many ceramic production processes and the process control links vary with product types. With the rapid economic development, customer needs are showing a trend of diversification and dynamics. Small batch and multi-variety order-based production of ceramic products has become increasingly popular7. The organization of ceramic production has become more difficult. Enhancing ceramic production and manufacturing capabilities through information technology has become an important issue for the industry. And MES has extremely strong application value as its technical support. ISA95 is the most influential MES standard in the industry, and has been successively accepted as a national standard by more than 100 countries including China. 8

At present, domestic research on the ISA95 standard mostly stays at the level of method introduction and principle introduction9, and there is still insufficient research on the extension and application of the standard. This article is based on ISA95, combined with the problems existing in the production of ceramic products, to study the models and implementation techniques of ceramic MES system. This article establishes a general model under the guidance of the ISA95 standard framework, schedules production according to finite capacity, and in specific production, performs personalized process configuration according to product characteristics, and then achieves personalized production.

\section{Problem description}

Company A is located in Chaozhou City of China and is a specialized ceramic company integrating production, processing and sales. Specializing in the production of ceramic sanitary ware products, various models are sold at home and abroad. Like most domestic ceramic production companies, they face the following difficulties:
- Diversified and dynamic customer needs.

- Ceramic product orders are small batches and many varieties. Production scheduling is difficult.

- $\quad$ Each process is relatively independent, making production dispatching difficult.

- Low degree of information make the information islands still exist.

With the opportunities of Industry 4.0 and Made in China 2025, Company A actively improves the intelligent manufacturing and information level of ceramic production.

\section{Model and implementation}

\subsection{Introduction to ISA95 and models}

ISA95 is an international standard for the integration of enterprise systems and control systems. It was voted and approved by the Instrumentation, Systems and Automation Society (ISA) in 1995. And 95 represents the 95th standard project of ISA. The ISA95 international standard defines the terms and models used when integrating enterprise-level business systems with factory floor-level control systems.1-6

The ISA95 standard provides clear model structures and clearly identifies the boundary between the enterprise domain and the manufacturing operations and control domain. These models are the hierarchy models, functional data flow model, manufacturing operations, information model.1 According to the ISA95 standard, the main operational activities in the manufacturing process can be divided into four types in parallel: production, quality, inventory, and maintenance. The data in each manufacturing activity can be divided into five types of resource data: materials, equipment, personnel, physical assets, and process segments, and four types of information flow data: activity definition, activity capability, activity schedule, and activity performance. ISA95 also describes in detail these models and their

"Corresponding author's e-mail: qw.yu@giim.ac.cn 
objects, as well as the object model interrelationships. 2310

\subsection{Development Platform}

After comprehensively considering system requirements for data security, functional scalability, and concurrent performance, the $\mathrm{PC} /$ mobile terminal front-end framework adopts cross-platform, fast and high- performance Angular9. The UI framework adopts Angular-based Nebular, NG-ZORRO-ANTD and NGZORRO-MOBILE. The back-end framework adopts Express, and the realization technology language adopts Node.js. The database adopts MongoDB with highperformance data storage.

\subsection{Common object models and order flow}

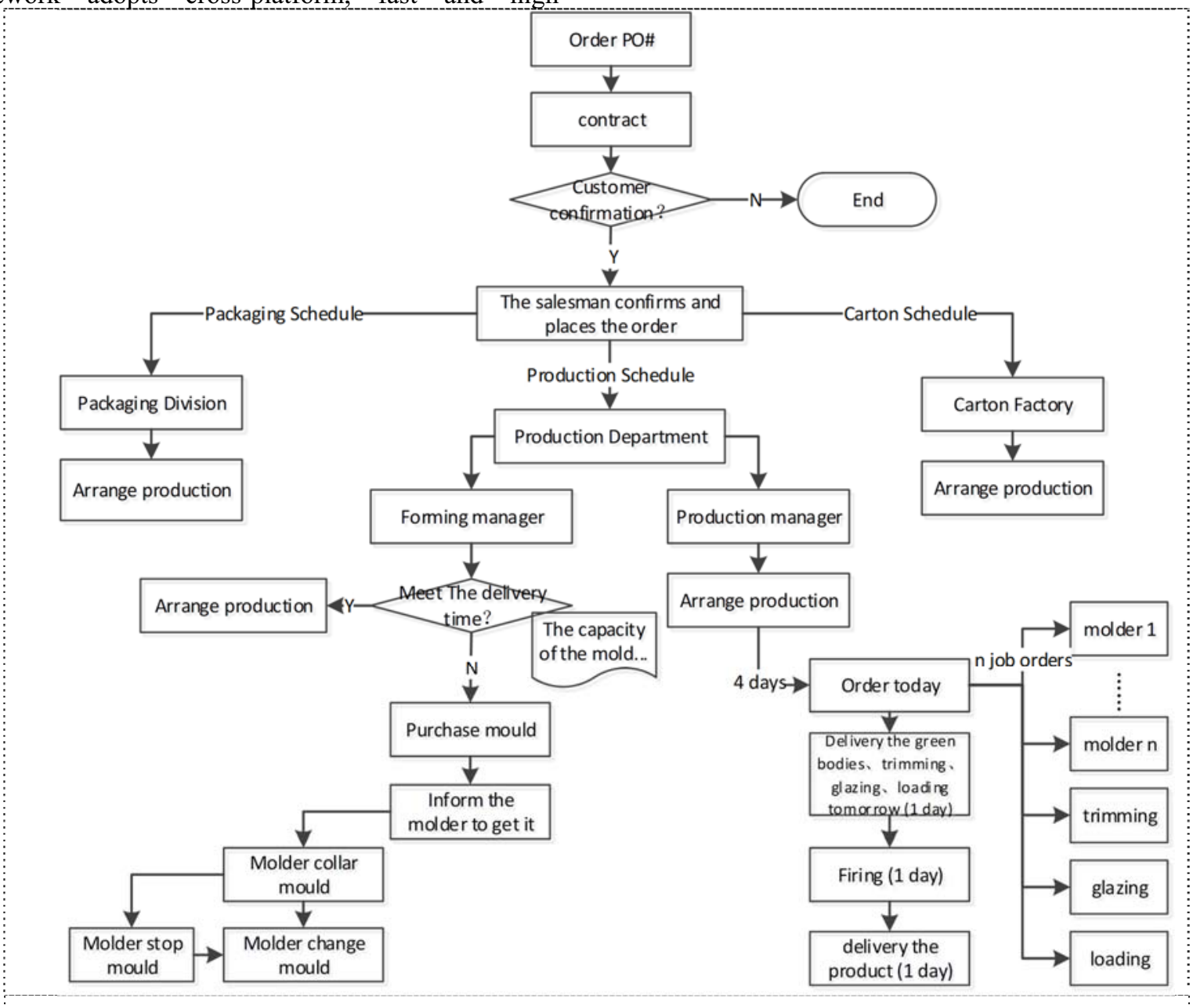

Fig 1. Order flow

Based on ISA95, the MES system established general hierarchy scope model, parameter model and common resource models (personnel, equipment, material, physical asset, process segment). All these common object models would be used in activity models. The research uses barcodes as the unique identification in the process of ceramic design, production and sales. Through cyberphysical technology, it improved the data utilization rate in the ceramic production process, realized the traceability and data statistics of the whole life cycle of ceramic production, and realized product traceability.

The order flow of company A is shown in Figure 1. Company A arranges packaging schedule and carton schedule according to customer orders synchronized from ERP, and arranges production schedule according to customer orders and company inventory plans. Production is divided into forming production and product production to meet the delivery date. The following mainly introduces product production.

\subsection{Detailed production scheduling and finite capacity scheduling}

The multi-variety and small-batch production model puts forward higher requirements for production scheduling, but the current scheduling model focuses on the product or process level.11 ISA95 proposes more in-depth finite capacity scheduling. Detailed production scheduling takes the production schedule and determines the optimal use of local resources to meet the production schedule requirements. Detailed production scheduling takes into account local situation and resource availability. This may include information about equipment, material, personnel and process segments. 23 


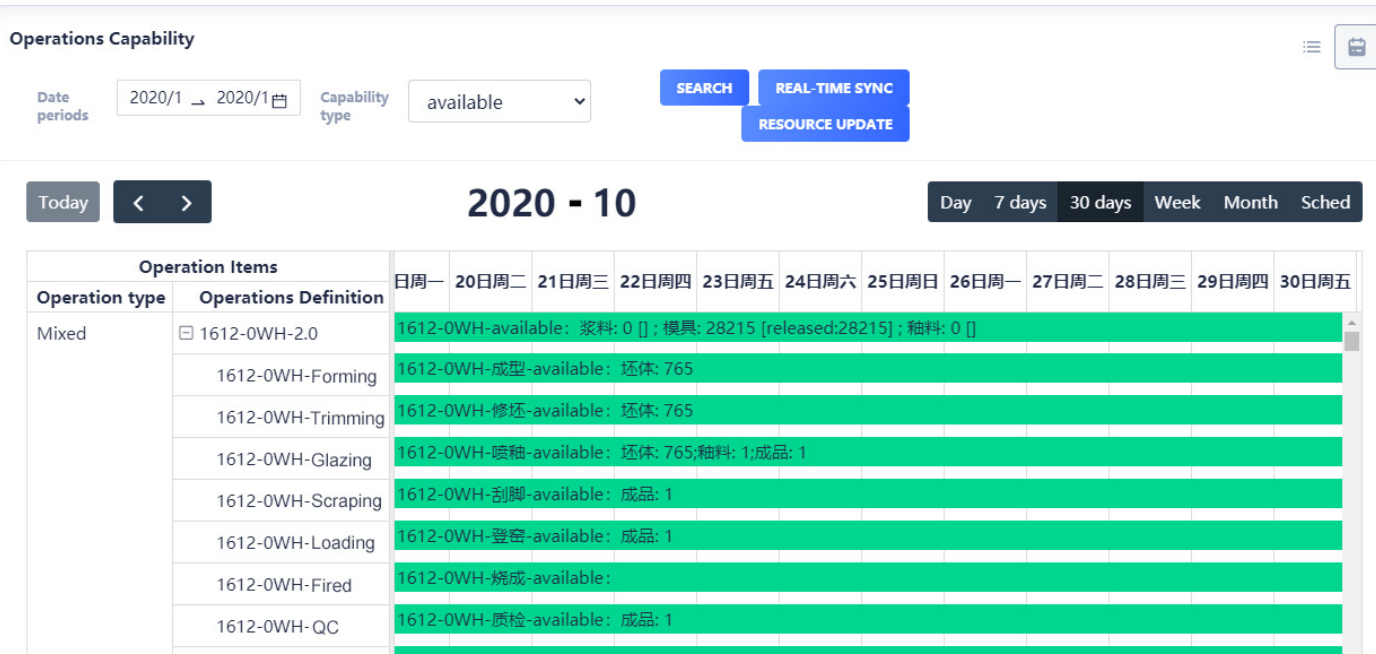

Fig 2. Operations Capability

Premium product inventory list

\begin{tabular}{|c|c|c|c|c|c|c|c|c|c|c|c|c|}
\hline $\begin{array}{l}\text { Ope } \\
\text { rate }\end{array}$ & ID & $\begin{array}{l}\text { Total to be ship } \\
\text { ped/PCS }\end{array}$ & $\begin{array}{l}\text { Emergency out (wit } \\
\text { hin } 7 \text { days) }\end{array}$ & $\begin{array}{l}\text { Emergency out (with } \\
\text { in } 15 \text { days) }\end{array}$ & $\begin{array}{l}\text { Packe } \\
\text { d/PCS }\end{array}$ & $\begin{array}{l}\text { Availabl } \\
\text { e/PCS }\end{array}$ & $\begin{array}{l}\text { LackedQt } \\
\text { y/PCS }\end{array}$ & $\begin{array}{l}\text { Fired/ } \\
\text { PCS }\end{array}$ & $\begin{array}{l}\text { Galze } \\
\text { d/PCS }\end{array}$ & $\begin{array}{l}\text { Dry bod } \\
\text { y/PCS }\end{array}$ & $\begin{array}{l}\text { Wet bod } \\
\text { y/PCS }\end{array}$ & $\begin{array}{l}\text { mould/ } \\
\text { PCS }\end{array}$ \\
\hline$\theta$ & 1633-0WH & 33710 & 33710 & 33710 & 7577 & 7153 & -18980 & 0 & 0 & 5673 & 0 & 48 \\
\hline$\theta$ & 1601-0WH & 26456 & 26456 & 26456 & 2990 & 12812 & -10654 & 0 & 0 & 3628 & 0 & 23 \\
\hline$\theta$ & A2011WH & 9000 & 9000 & 9000 & 76 & 68 & -8856 & 0 & 0 & 283 & 0 & 218 \\
\hline 8 & 1628-0WH & 8393 & 8393 & 8393 & 617 & 90 & -7686 & 0 & 0 & 1808 & 0 & 8 \\
\hline 0 & B2004-01WH & 4068 & 4068 & 4068 & 135 & 113 & -3820 & 0 & 0 & 813 & 0 & 124 \\
\hline
\end{tabular}

Fig 3. Premium product inventory list

In most ceramic production companies, resource capacity depends on finite material and equipment capacity, and other resources are sufficient. The system makes detailed statistics of the finite material capacity information required by detailed production scheduling, as shown in Figure 2. It also provides the inventory list of high quality products and qualified products for adjusting production scheduling, as shown in Figure 3.

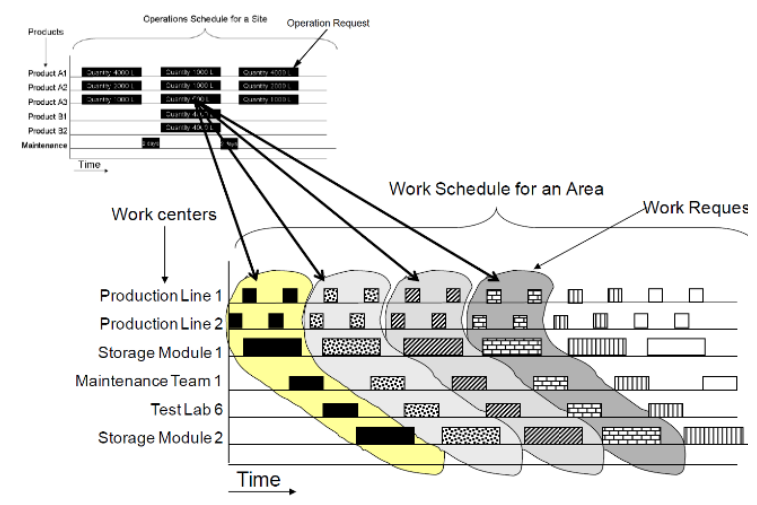

Fig 4. Work schedule for an area4

\subsection{Work schedule and job list models}

The work schedule may apply to scheduling of production, maintenance, quality test and inventory, or to other extended categories of activities. As shown in Figure 4, one operation request is implemented in multiple work requests. Each work request is made up of multiple job orders. And each job order is associated with a work master, as shown in Figure 5. Work master defines workflow for job.

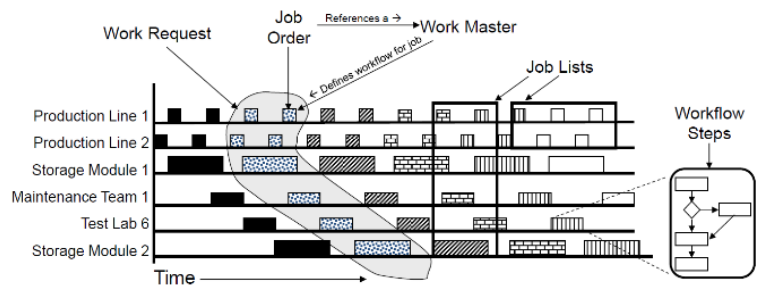

Fig 5. Work request, job order, job list4 


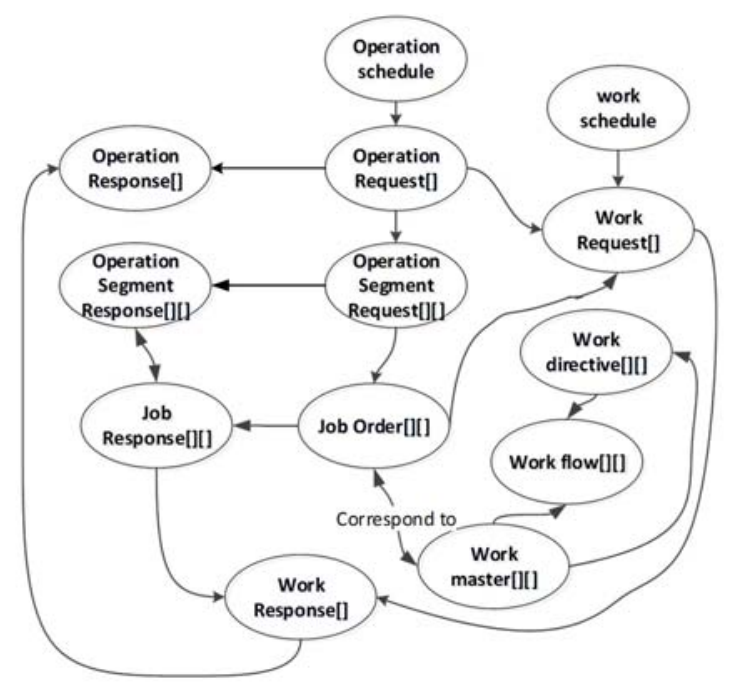

Fig 6. Products dispatching.

According to work schedule model, the ceramic MES system implement the functions, which for combined products dispatching, including separate products dispatching, as shown in Figure 6:

- Step 1. Obtain the operation requests that need patching according to order ids.

- $\quad$ Step 2. Generate job order according to operation segment requirements of operation requests. Job list includes job order. Job order generates job response and corresponds to work master.

- $\quad$ Step 3. Create work requests based on operation requests and generated job orders.

- Step 4. Create work response based on work request and generated job responses.

- Step 5. Create operation responses based on the operation requests.

- $\quad$ Step 6. Add these data to the database.

\subsection{Job order and workflow}

As shown in Figure 5 and Figure 6, a job order is the smallest unit of work in a job list and a work request. It references an associated work master. The work master defines workflow for job. In the ceramic MES system, the job order is implemented on the mobile terminal.

The mobile terminal is responsible for job order execution such as forming, delivery, trimming, glazing, scraping, loading, quality control, routing inspection, as

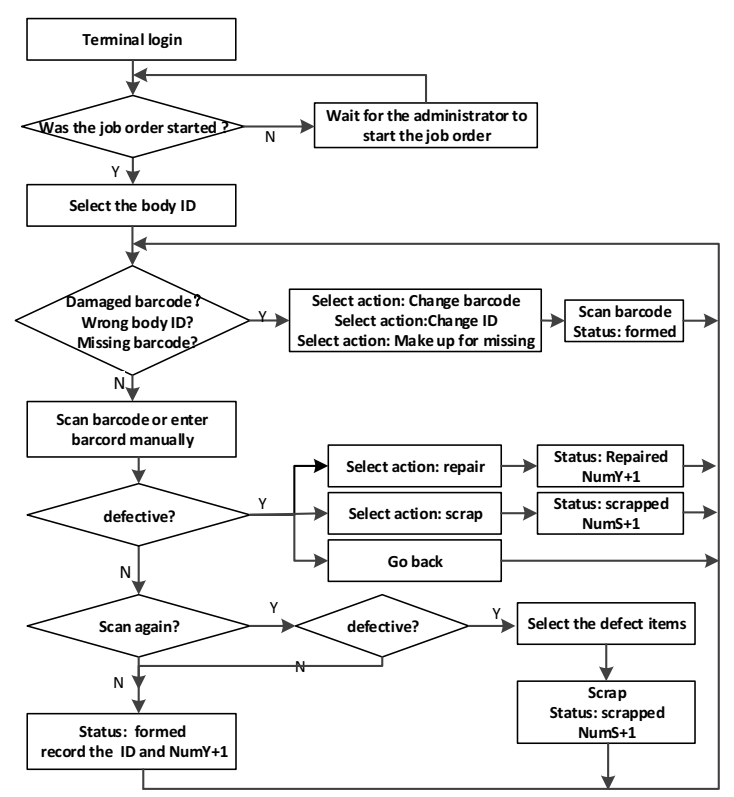

Fig 7. Forming process workflow

well as inventory. The terminal deal with process information such as quantities, material, event data, operator entered data, transaction data, operator actions, messages, calculation results from models and other data of importance in the making of a product. Its data collection is time- or event-based, with time or event data added to give context to the collected information.

In the MES system the terminal workflow is started or completed by the process manager. And then the operations are completed by the process operator. During the processing, it collects the required information. Forming is one of the ceramic production processes, its workflow is shown in Figure 7.

\subsection{Production tracking and production performance analysis}

Based on barcode, resource models, activity models and data collection, the MES system achieved production tracking, which included summarizing and reporting information about personnel and equipment actually used to produce product, material consumed, material produced etc. And its Production performance analysis included analysis of production progress, resource utilization, equipment performance, procedure efficiencies, quality report and analysis, employee performance and production variability, etc. Such as the real-time quality display board, shown in Figure 8. 


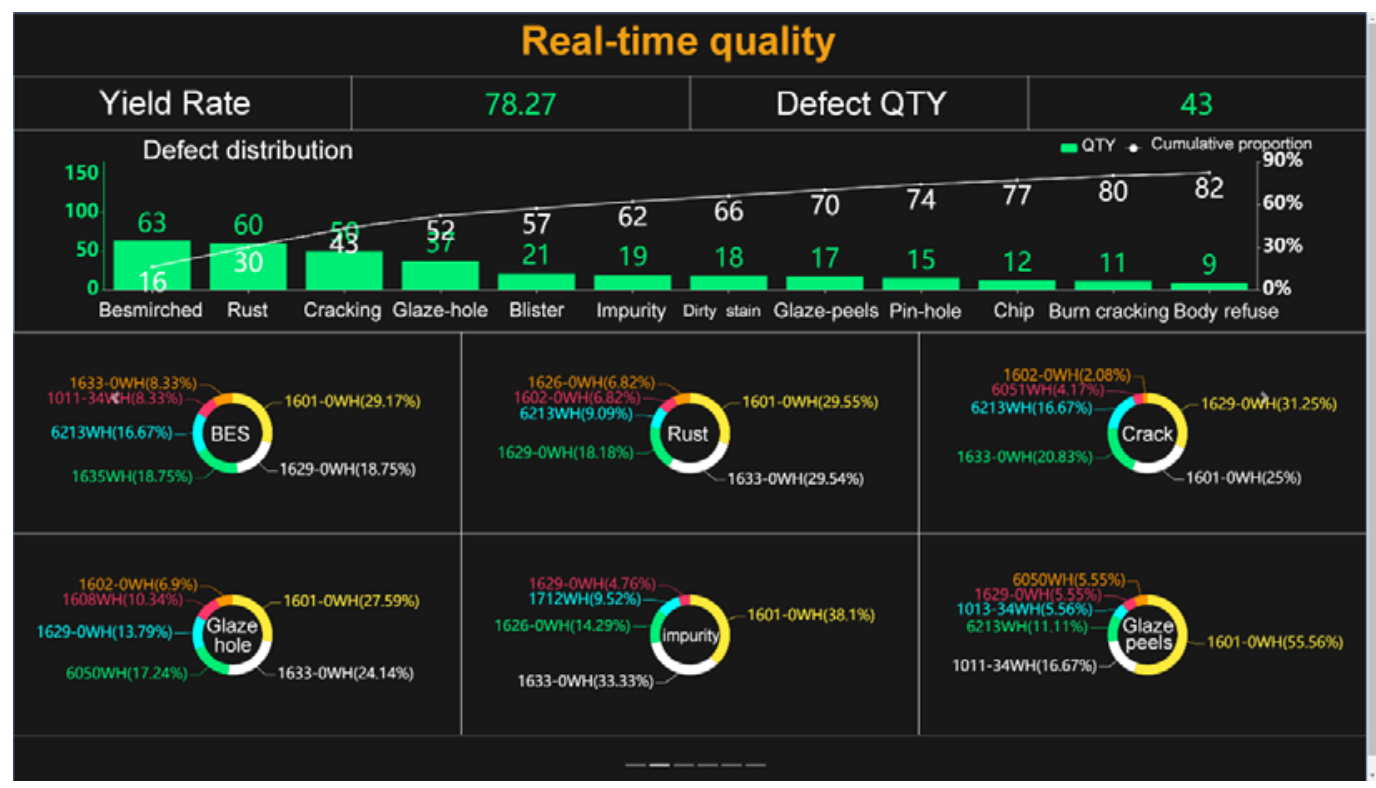

Fig 8. Real-time quality display board.

\section{Application effect}

This MES system has been put into use in company A. It uses ISA95 standardized models to establish general hierarchy scope model, parameter model, resource models and common operations models. According to the production processes and the ceramic technology, a production flow suitable for the individuality of the ceramic company has been established. The MES system has realized one-click generation of orders, semiautomatic production scheduling according to finite capacity, one-click dispatching, and reduce repeated entry operations. It has made the process seamless, flexible and simple, and has realized high flexibility and intelligent ceramic manufacturing. With the use of barcodes and models, The MES system has improved the data utilization rate in the ceramic production process, has realized the full life cycle traceability and data statistics of ceramic production, and realizes product traceability.

\section{Result comparison}

This article is based on ISA95, combined with the problems existing in the production of ceramic products, to study the models and implementation techniques of ceramic MES system. The successful application of the ceramic MES system in company A has realized the standardized configuration and personalized production of the ceramic industry, realized the high flexibility and intelligence of ceramic manufacturing, and the traceability of ceramic products, and improved the information level of the ceramic industry.

Further studies on the implementation of finite capacity scheduling will be carried out, to realize fully automatic scheduling, and to further improve the intelligent level of the ceramic industry.

\section{Acknowledgments}

This work is supported in part by the frontier and key technological innovation special foundation of Guangdong province (Major science and technology project), China, Grant 2016B090912006, the GDAS' Project of Science and Technology Development, China, Grant 2017GDASCX-0115 and the GDAS' Project of Science and Technology Development, China, Grant 2018 GDASCX-0115.

\section{References}

1. ANSI/ISA-95.00.01-2010 (IEC 62264-1 Mod). (2010) Enterprise-Control System Integration - Part 1: Models and Terminology [S]. ISBN: 978-1-93600747-9.

2. ANSI/ISA-95.00.02-2010 (IEC 62264-2 Mod). (2010) Enterprise-Control System Integration - Part 2: Object Model Attributes [S]. ISBN: 978-1-93600748-6.

3. ANSI/ISA-95.00.03-2013 (IEC 62264-3 Modified). (2013) Enterprise-Control System Integration - Part 3: Activity Models of Manufacturing. ISBN: 978-0876640-33-3.

4. ANSI/ISA-95.00.04-2012. (2012) Enterprise-Control System Integration - Part 4: Objects and attributes for manufacturing operations management integration[S]. ISBN: 978-1-937560-62-1

5. ANSI/ISA-95.00.04-2018. (2018) Enterprise-Control System Integration - Part 4: Objects and attributes for manufacturing operations management integration[S]. ISBN: 978-1-64331-026-8.

6. ANSI/ISA-95.00.05-2018. (2018) Enterprise-Control System Integration - Part 5: Business-to- 
Manufacturing Transactions[S]. ISBN: 978-1-64331047-3.

7. Xia Jianhua, Wen yizhang. (2018) Status and development trend of intelligent manufacturing in ceramic industry. Foshan Ceramics, 28(12):8-10.

8. Zhang Lunyan. (2011) Study of Aeronautic MES Standard. Aviation Standardization and Quality. (06):27-30.

9. Su Hong-ye, Xiao Li-yong, Miao Yu. (2010) Overview on research and application of manufacturing operations management. Manufacturing automation, (4):8-13,95.

10. Song Min, Wang Shewei. (2013) Data analysis method to assembly process based on ISA95. Computer engineering and design, 9,34(9):33433347.

11. Wei Wei. (2020) A Research of Production Scheduling Algorithm for Lean Production Management System. University of Electronic Science and Technology of China. Chendu. 